\title{
Knowledge And Attitude Of Nigerian Ophthalmologists Towards Cornea Donation And Corneal Graft.
}

\author{
JOSEPH M. WAZIRI-ERAMEH, AFEKHIDE O. ERNEST , OMOLABAKE T. EDEMA
}

\begin{abstract}
The aim of this study was to determine the attitude of practicing Nigerian ophthalmologists towards cornea donation and corneal graft. The responses of 160 ophthalmologists (specialists and senior registrars) in Nigeria who responded to an appropriate questionnaire on cornea donation at one of their National conferences attended mainly by practicing ophthalmologists were analysed. Through the questionnaire, the knowledge and attitude of the ophthalmologists towards cornea donation and cornea graft in Nigeria were evaluated. The questionnaire also included questions on donor materials from prisoners for themselves and their close relatives. One hundred and sixty (160) of the 191 ophthalmologists (84\%) given the questionnaire responded. All the respondents have adequate information on cornea donation and corneal graft. Majority of them were favourably disposed to most of the questions asked except when it came to carrying a donor card, signing the donor form and the actual signing of the form. Only 34 (21\%) of ophthalmologists agreed to donate their cornea at death. It was found that traditional beliefs, social implications and personal considerations mainly influenced those who were not favourably disposed to cornea donation and corneal graft. The majority of practicing ophthalmologists in Nigeria are not favourably disposed to donating their cornea at death.
\end{abstract}

\section{INTRODUCTION}

Between forty-one and fifty-two million people are blind or visually impaired in the world ${ }^{1}$. About thirty-four million of them are blind from conditions that are preventable or treatable. The majority of the world's blind

KEYWORDS: Cornea donation, corneal graft. Ophthalmologists. Executed prisoners, donor cards.

Departments of Ophthalmology University of Benin Teaching Hospital, Benin City, Nigeria

All Correspondence: Dr. Joseph M. Waziri-Erameh, Dr. Afekhide O. Enerst, Dr. Omolabake Tolutope E. Departments of Ophthalmology University of Benin Teaching Hospital, Benin City, Nigeria live in developing countries where health care and medical resources are scarce.

There are also about ten million cornea blind worldwide of which a substantial percentage has light perception vision. A large percentage of this ten million cornea blind are in the less developed world where nontransparent cornea represents a significant percentage of incurable blind ${ }^{2}$. Nigeria is a developing country; corneal opacity is a common cause of blindness in Nigeria today ${ }^{3}$.

In the less developed world including Nigeria 
apart from lack of donor materials, the long term poor results of previous keratoprosthesis partly explain why corneal blinds are neglected ${ }^{4,5}$. Conditions that primarily affect the cornea were found to be responsible for blindness of 1 in every 35 persons in a survey population in Communities' Mesoendemic for Onchocerciasis in Northern Nigeria ${ }^{6}$. The conditions included anterior segment Onchocerciasis, trachoma, and measles / Xerophthalmia.

The use of homologous donor cornea grafts started since the pioneering work of Zirm in $1905^{7}$. Zirm, working in a Moravian town in Slovakia in 1905, transplanted the clear cornea of an 11-year-old boy to a man who was blinded in both eyes by lime injury. A year later, the graft remained clear with vision improved from hand movement to $6 / 36^{9}$. Reisinger ${ }^{10}$ is credited with the controversial suggestion of using cornea from other species (heterograft). Kissan ${ }^{11}$ in 1884 attempted a heterograft using a six months old pig cornea which failed. There were many other penetrating cornea grafts attempts in the nineteenth century but many failed and the workers were discouraged ${ }^{12,13,14}$.

In 1935 Filatov insightfully introduced the use of cadaver donor corneas ${ }^{15,16}$. In Nigeria, donor cornea is a serious problem and the usual effort is optical iridectomy as a way around corneal opacities but this is useless if the opacity is large.

The most significant work to date on cornea donation in Nigeria is the multi center survey by Babalola et $\mathrm{al}^{3}$. Babalola et al in a survey of cornea donation amongst Nigerians found that $37 \%$ of the respondents were ready to donate cornea and $30 \%$ ready to carry donor cards, a very encouraging finding for the prospect of cornea banking and cornea grafting in Nigeria.
This study was designed primarily to document the knowledge and attitude of ophthalmologists in Nigeria to cornea donation and corneal graft. It is also intended to indirectly verify the findings by other writers on the attitude of Nigerians in general to cornea graft and cornea donation; to examine if ophthalmologists in Nigeria are better informed about cornea donation and cornea graft and to determine their attitude in general. The information thus gathered will serve as good database for the proposed development of cornea banking in Nigeria.

\section{MATERIALS AND METHOD}

An appropriate questionnaire on cornea graft / donation and a "Cornea donation" slip of the Department of Ophthalmology of the University of Benin Teaching Hospital (figure1) were distributed to all the Consultant and senior Registrar grade ophthalmologists in the congress hall at an annual congress of the Ophthalmological society of Nigeria.

The retrieved forms were analysed according to sex and status of ophthalmologist (consultant, registrar), signing of donor forms, cornea from executed prisoners, cornea donation after death, receiving cornea graft and reasons for negative disposition (Tables I-VII)

The senior registrar grade ophthalmologists were those who have spent about 4 years in residency training in Ophthalmology. The junior residents were excluded, as we wanted those who have full and clear understanding of the issue.

\section{RESULTS:}

One hundred and sixty ( 1600$)$ Ophthalmologists (consultant and senior registrar grade) (83.8\%) responded out of the 191 to whom questionnaires were distributed. Sixty (60) of the respondents $(37.5 \%)$ were consultant ophthalmologists while the senior registrar grade 
ophthalmologists were 100 (62.5\%). Sixtysix (66) males (41.3\%) and 94 females (58.4\% ) responded to the questionnaire. The sex and status of the 31 non-respondents could not be determined ( figure 2 and tables I-VII )

\section{Figure 1:}

CORNEA GRAFTING IN AN INFORMED N I G E R I A N $\quad$ P O P U L A T I O N (OPHTHALMOLOGISTS)

1. Have you heard of Cornea Graft. Yes/No

2. Would you receive a graft if it will prevent you from going blind? Yes/No

If answer is No-give honest reason.

3. Would you allow your relation to receive a graft to have sight. Yes/No.

If answer is No, give reason
4. Would you give permission for a relation to donate one eye/both eyes after death to restore sight to a blind person? Both eyes/One eye/No If answer is one eye/ No give honest reason

5. Would you donate one eye/both eyes after death to restore sight to a blind person. Both eyes one eye/No.

If one eye/No give honest reason

6. Would you accept cornea from executed prisoners to have sight?

Yes/No If No give honest reason.

7. Would you allow a relation to accept cornea from an executed prisoner to save his sight.? Yes/No If No give reason

8. Status -Consultant: Senior Registrar

\section{Figure 2:}

\section{QUESTION AND ANSWER}

YES

NO/ NEGATIVE

\section{RESPONSE}

(1) Have you heard of cornea graft

160

(2) Would you receive a graft if it will prevent you from going blind

(3) Would you allow your relation to receive a graft to save sight

(4) Would you give permission for a relation to donate one or both eyes after death to restore sight to a blind person
Both eyes
One eye
$\left.\begin{array}{l}102 \\ 28\end{array}\right\}$ 
(5) Would you donate one eye or both eyes after death to restore sight to a blind person

Both eyes

One eye

(6) Would you accept cornea from executed prisoner to have sight

(7) Would you allow a relation to accept cornea from an executed prisoner to save his sight

(8) Would you in all honesty agree to carry a donor 78

\begin{tabular}{l|l|c}
\hline & NO & \% OF RESPONDENTS (160) \\
\hline Respondents & 160 & 100.0 \\
Non respondents & 31 & 19.4 \\
Specialist Ophthalmologists & 60 & 37.5 \\
Registrar Ophthalmologists & 100 & 62.5 \\
Male respondents & 66 & 41.3 \\
Female respondents & 92 & 58.8 \\
\hline
\end{tabular}

Table II SIGNING OF DONOR FORM RESPONDENTS

\begin{tabular}{l|c|c}
\hline & NO. & \%OF RESPONDENTS (160) \\
\hline Actually signed donor form & 34 & 21.3 \\
Yes to signing donor form & 80 & 50.0 \\
Yes to carry donor card & 78 & 48.8 \\
\hline
\end{tabular}

Table III GRADE OF OPHTHALMOLOGIST AND SIGNING OF DONOR FORM

\begin{tabular}{|c|c|c|c|c|}
\hline & NO & $\begin{array}{l}\text { YES TO SIGNING } \\
\text { DONOR FORM }\end{array}$ & $\begin{array}{l}\% \text { OF RESPONDENTS } \\
\text { BY GRADE }\end{array}$ & $\begin{array}{l}\text { \% OF TOTAL } \\
\text { RESPONDENTS (160) }\end{array}$ \\
\hline $\begin{array}{l}\text { Specialist } \\
\text { Ophthalmologist }\end{array}$ & 60 & 28.0 & 46.7 & 17.5 \\
\hline $\begin{array}{l}\text { Senior Registrar } \\
\text { Grade }\end{array}$ & 100 & 52.0 & 52.0 & 32.3 \\
\hline
\end{tabular}


30 Journal of Medicine and Biomedical Research

Table IV CORNEA FROM EXECUTED PRISONER

\begin{tabular}{l|c|c}
\hline & NO. & \% OF RESPONDENTS (160) \\
\hline Yes for self & 106 & 66.3 \\
Yes for relation & 124 & 77.5 \\
\hline
\end{tabular}

Table V CORNEA DONATION AFTER DEATH

\begin{tabular}{l|c|c}
\hline & NO & \% OF RESPONDENTS (160) \\
\hline Yes for self & 106 & 66.3 \\
One eye & 28 & 17.5 \\
Both eyes & 78 & 48.8 \\
Yes for relation & 130 & 81.3 \\
One eye & 28 & 17.5 \\
Both eyes & 102 & 63.8 \\
\hline
\end{tabular}

Table VI RECEIVING CORNEA GRAFT

\begin{tabular}{l|c|c}
\hline & NO. & \% OF RESPONDENTS (160) \\
\hline Yes for self & 160 & 100.0 \\
Yes for relation & 160 & 100.0 \\
\hline
\end{tabular}

Table VII TABLE OF REASONS GIVEN BY THOSE NEGATIVELY DISPOSED TOCORNEA DONATION/CORNEAL GRAFT

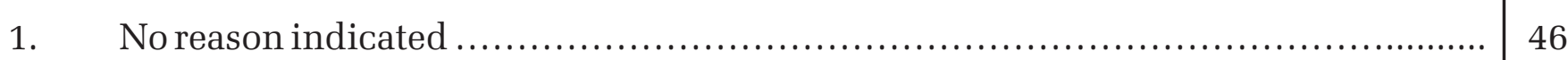

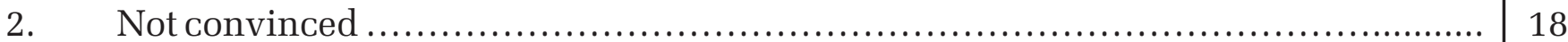

3. One eye only in case; no one knows (Fearing reincarnation).......................... 12

4. Prisoner not member of society to identify with.................................. 39

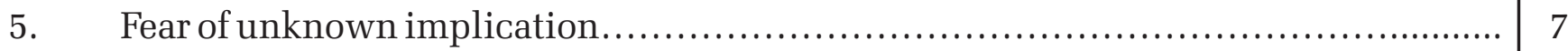

6. Not previously accepted by relative before death .............................. 6

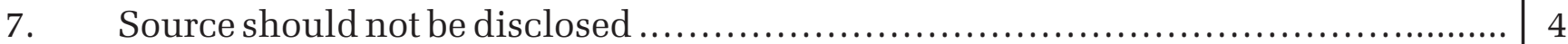

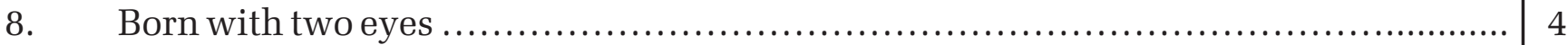




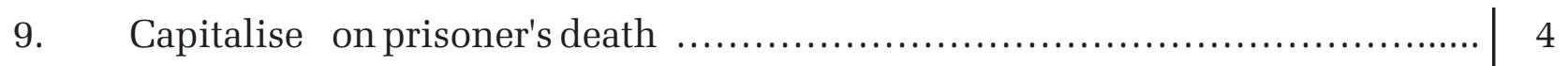

10. Not accepted in community ............................................ 3

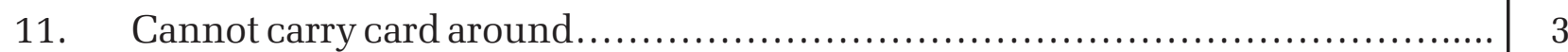

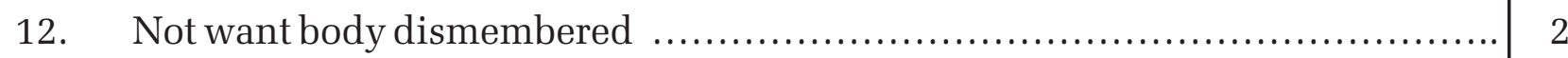

13. Not sure HIV free.................................................... 2

14. Not have evil eye like the prisoner ....................................... 2

15. To prevent mutilation before burial ...................................... 2

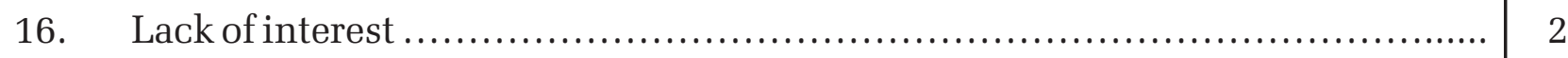

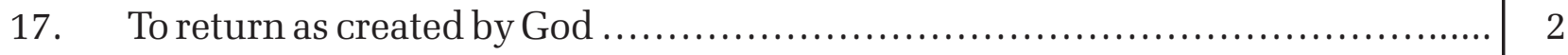

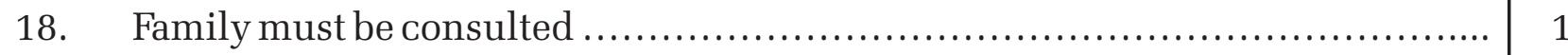

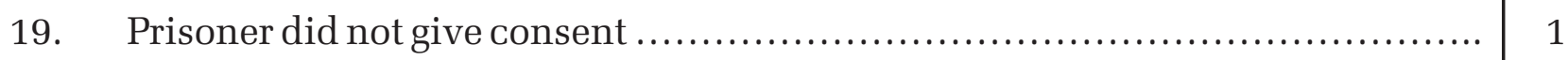

20. Not ethical removing criminal's eye ..................................... 1

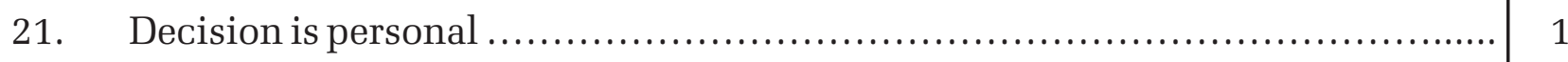

All the respondents have heard of cornea graft, all were willing to receive cornea graft to prevent blindness and all were willing for close relatives to receive cornea graft.

One hundred and six of the 160 respondents were willing to donate their eyes after death (both eyes 78 (73.6\%) and one eye $28(26.45 \%)$.

One hundred and thirty (130) of the 160 respondents $(81.3 \%)$ were willing to give permission for close relatives to donate eyes after death. One hundred and two (102) respondents (78.5\%) will give permission for both eyes to be donated while 28 (21.5\%) will give permission for only one eye to be donated).

One hundred and six (106) of respondents (66.3\%) would accept donor cornea for self from executed prisoners while 124 respondents $(77.5 \%)$ would allow relatives to receive cornea from executed prisoners.

Seventy-eight of the 160 respondents $(48.8 \%)$ would agree to carry donor cards and said 'Yes' to signing the attached donor form, but only 34 of the 160 respondents (21.3\%) actually signed the donor forms to be handed over to department of ophthalmology of the University of Benin Teaching Hospital.

\section{DISCUSSION}

The work of Babalola et $\mathrm{al}^{3}$ is the most significant to date survey of reference as regards corneal donation and corneal graft in Nigeria. It was a multi-centre study, which involved five teaching hospitals. Large majority of the respondents were in the very large cities that had the university teaching hospitals that carried out the multi-centre 
surveys. In the survey they tried to establish the knowledge and attitude of Nigerians as regards cornea donation and cornea graft. In the study, they found a high percentage, 37\% willing to donate eyes after death but also noted that a substantial proportion in all probability may be unwilling when it comes to the decision time (i.e. signing the donor form) We find the $37 \%$ rather suspect in a country where little or no attempt has been made to educate the populace on cornea donation. In that study (Babalola et al) we believe many of the respondents were either ignorant or not serious and not honest in their answers to the questions. This partly informed our decision to carry out knowledge and attitude study on a group that should understand what cornea donation and cornea graft is about. Our findings would be the best of the most optimistic view on acceptability of cornea donation and corneal graft in Nigeria considering the special interest of Ophthalmologists in the matter. It will also provide a realistic reference data for future plan in cornea banking.

Eighty-one percent (81\%) of respondents were willing to donate cornea of close relatives after death while $66 \%$ were willing to donate their own cornea after death. We could not find the reason for this disparity. One would have expected a reversed finding, that is, more respondents willing to donate their own eyes and less for their close relatives. Another curious finding in that $78 \%$ of respondents would give permission for close relatives to receive donor cornea from executed prisoners while 66\% would accept donor cornea from executed prisoners for self. Some of the reasons given by those who said no to donor cornea from prisoners (table G) include: prisoner not fit and proper person to identify with; did not want to have evil eye like the prisoner; unfair to exploit dead prisoners, the prisoners did not give consent and that it was unethical. These must include some of the reasons why
$34 \%$ of respondents refused for self to be grafted with donor corneas from executed prisoners. We are however at a loss why $12 \%$ of respondents who said no for self, said yes for close relatives. Forty-nine percent (49\%) of respondents would donate both eyes while $18 \%$ would donate only one eye. The probable reason for this may be built on the belief of reincarnation or life after death held by many of our people. (They do not want any ocular deficit at reincarnation). The belief in reincarnation or life after death is strong and wide spread enough to include Ophthalmologists. This belief is responsible for poor organ donation in the developing World.

In this study 80 ophthalmologists ( $42 \%$ of ophthalmologists given questionnaires) answered yes to signing donor form and 78 (41\%) answered yes to carrying donor card. When it came to actual signing of the donor forms provided, only 34 (21\%) of ophthalmologists given the questionnaires signed the donor forms and handed them over to the University of Benin, department of Ophthalmology.

Our finding of $41 \%$ willing to donate eyes (yes to signing or carrying a donor card agrees with the finding of Babalola et $\mathrm{al}^{3}$ who found $37 \%$ willing in the general Nigerian population. Our finding of $41 \%$ is a bit higher because of the uniqueness that it is a group of Ophthalmologists who fully understand the subject matter, and also probably sample size. Only $21 \%$ of ophthalmologists given questionnaire signed the donor slip, a far cry from those who said they were willing to sign the donor forms (41\%). This finding is more likely to be the true reflection or position of the situation as regard cornea donation in Nigeria.

Babalola et al found that education played no significant role in cornea donation. This is similar to our finding in the sense that being a registrar grade ophthalmologist or a specialist ophthalmologist did not 
significantly affect those who answered yes to donation. Twenty-eight (47\%) out of the 60 specialist ophthalmologists that responded; said yes to cornea donation and 52 registrar grade ophthalmologists (52\%) out of 100 , said yes to cornea donation. Ordinarily, a large percentage of willing donors is expected from the specialist ophthalmologists, as they should be more aware and more motivated. Analysis of the reasons given for refusal for self and for close relatives to donate cornea or accept cornea from executed prisoners (table G) showed about 21 in all. If Ophthalmologists hold these views, one wonders what the non-medical and largely illiterate and semi-illiterate Nigerian population would hold. The $41 \%$ of total Ophthalmologists willing to carry donor card in this study and the $37 \%$ found in the general Nigerian population ${ }^{3}$ wiling to donate cornea after death may not be accurate assessment of their beliefs. This study showed only $21 \%$ of Ophthalmologists signed the donor forms.

These 21\% are the reliable percentage of Ophthalmologists willing to donate cornea after death. If only $21 \%$ of Ophthalmologists (the end users whose patients receive the donor corneas) are actually willing to donate cornea after death, then a lot of campaigning, education and orientation are needed by the Ophthalmologists. When this has been successfully done, the general Nigerian population will be targeted and educated on cornea donation.

In conclusion, the finding of $21 \%$ of Nigerian Ophthalmologists (in this study) willing to donate cornea is more realistic. The $37 \%$ ascribed to Nigerians willing to donate cornea after death is unreliable and misleading and any calculation, planning or project based on it may experience serious difficulties or out right failure.

\section{References}

1. Larry Schwabb In Eye care in Developing Countries, Oxford University Press 1990;10

2. Van Andel MV, Worst J. Sign I. Artificial Corneas for the third world: Anales del instituto Barraquer 1999; 177-179

3. Babalola O.E, Samaila E. Ezepue E, Waziri-Erameh J, and Abiose A. Acceptability of post Mortem donation of cornea among Nigerians. Nigeria Journal of Ophthalmology 1995; 3(2):26-34.

4. Renard G. Artificial Cornea. Bull Acad. Nathl Med 1996;180(33):659-68.

5. Corrazza E, Petitti Alberto A, Filadoro P, Colliardo P. Complications of Facinelli's OsteoodontoKeratoprothesis. Anles del instituto Barraquer. 1999;28;96-99

6. Abiose A, Murdoch I, Babalola O E. Distribution and aetiology of blindness and visual impairment in mesoendermic onchocercal communities; Kaduna State of Nigeria. Br J. Ophthalmol 1994;78(1): 8-13.

7. Duke Elders WS. Diseases of the outer eye, part 2. In system of Ophthalmology 1965;8:646. St. Louis CV Mosby.

8. Zirm E. Eine erfolgreiche total kertoplastik. Graefes Arch Clin Exp Ophthalmol 1906;64:580-93

9. Golgar CA, Braur K, Zirm EK. Centennial review of corneat transplantation Arch Ophthalmol 1965;74:871-4

10. Reisinger F. Die keratoplastik ein 
Versuch zur Erweiterung der Angenheilkunst. Bayerische Annalen 1824;1:207-15

11. Kissan RS. Keratoplastic in man. NY J Med 1844; 2:281-2

12. Castroviejo R. Keratoplastic. An historical and experimental study, including a new method. Part 1. Am J Ophthalmol 1932; 15:825-38

13. Paton RT. Keratoplastic. The Blakiston, New York: McGraw Hill book Co. Inc.1955; 1-35.
14. Rycroft B. Doyne Memorial LectureThe cornea Graft-Past, Present and Future. Trans Ophthalmol Soc. UK 1966; 85:459-517

15. Filatov VP. Transplantation of the cornea. Arch Ophthalmol 1935; 13: 321-47

16. Filatov VP. Transplantation of the cornea from preserved cadaver's eyes. Lancet 1937;1:1395-97. 